\title{
COMPARISON OF COMMON CAROTID ARTERY INTIMA-MEDIA THICKNESS BETWEEN BRAZILIAN EURO-DESCENDANTS AND AFRO-DESCENDANTS WITH ATHEROSCLEROSIS RISK FACTORS
}

\author{
Ivan Benaduce Casella, Fabio José Bonafé Sotelo, Yumiko Yamazaki, Calógero \\ Presti, Alecxander Vassoler, Henry Augusto Hoffmann Melo
}

doi: 10.1590/S1807-59322009000700009

Casella IB, Sotelo FJB, Yamazaki Y, Presti C, Vassoler A, Melo HAH. Comparison of common carotid artery intima-media thickness between brazilian euro-descendants and afro-descendants with atherosclerosis risk factors. Clinics. 2009;64(7):65764.

OBJECTIVE: To compare common carotid intima-media thickness (IMT) between the two major Brazilian ethnic groups (those of African descent and those of European descent) among individuals with one or more risk factors for atherosclerotic disease.

METHOD: Two hundred and six patients with one or more risk factors for atherosclerotic disease were evaluated in a cross-sectional study in which their clinical, ethnic and Demographic characteristics were collected. All patients underwent duplex ultrasound examination of their carotid vessels to obtain IMT measurements.

RESULTS: One hundred and fifty-three patients (74.3\%) had a carotid IMT greater than $1.0 \mathrm{~mm}$ at one or more point of measurement in at least one common carotid artery. There was a significant correlation between older age and mean carotid wall thickness $(\mathrm{R}=0.479$ / $\mathrm{P}<0.01)$. Multivariate analysis identified male sex, arterial hypertension and older age as variables associated with increased IMT ( $\mathrm{P}<0.05$ for all variables). When IMT was compared between the two ethnic groups in this study, no significant differences were noted. Euro-descendants and Afro-descendants had similar IMT values, even when the groups were stratified by degree of IMT (normal vs. increased) and presence of stroke and/or transient ischemic attack (yes vs. no).

CONCLUSIONS: The risk factors associated with increased common carotid artery IMT in Brazilian individuals are similar to those in previously described populations. No differences were observed between the two main Brazilian ethnic groups. Longitudinal studies are required for a better evaluation of the incidence, etiologic factors and evolution of carotid intimomedial thickening in this population.

KEYWORDS: Intima-media thickness; Carotid; Atherosclerosis; Ethnic groups; Ultrasound

\section{INTRODUCTION}

Since the first studies comparing anatomical and ultrasound measurements of the carotid intima and media layers were undertaken, ${ }^{1,2}$ intima-media thickness (IMT) has demonstrated its usefulness as a marker for cardiovascular risk and as a method for detection of the early development of arterial atherosclerotic disease. ${ }^{3}$ Several investigations have provided evidence of an association

Division of Vascular Surgery, Hospital Regional Sul - São Paulo/SP, Brasil. Email: ivancasel@uol.com.br

Tel: 55115694.8229

Received for publication on January 29, 2009

Accepted for publication on April 16, 2009 between increased IMT and classical risk factors associated with the development of atherosclerotic disease and the occurrence of cardiovascular events. ${ }^{4-8}$

Additionally, IMT regression or delayed IMT progression can be observed when risk factors are controlled via lifestyle modifications or inhibited by different pharmacologic therapies. These findings demonstrate the usefulness of repeated IMT measurements in the evaluation of a patient's response to therapy. ${ }^{9-12}$

Studies conducted in multiple countries have shown that IMT values may differ between distinct ethnic groups, ${ }^{13-15}$ thus indicating the need for regional investigations. Many regional patient populations have been investigated; however, investigations examining increased IMT in Brazilian 
individuals are few and limited to the evaluation of certain clinical characteristics. ${ }^{16-17}$ Because the Brazilian population possesses multiethnic characteristics, such racial differences should be taken into account in studies evaluating IMT.

The objective of this investigation was to measure and compare common carotid artery IMT (CCA IMT) between the two major ethnic groups present in Brazil (Eurodescendants and Afro-descendants) in individuals with one or more risk factor for atherosclerotic disease, and to identify demographic and clinical factors that may be associated with increased IMT values.

\section{METHODS}

Between February and September of 2005, 210 patients were submitted to duplex scan ultrasound examination of their carotid vessels in our institution. The most common indications for ultrasound evaluation of the carotid arteries included the occurrence of a neurologic event [stroke, transient ischemic (TIA) attack or both], the assessment of cardiovascular status in patients with risk factors for atherosclerosis and the need for preoperative evaluation before vascular surgery. Four patients who underwent carotid duplex ultrasound examination due to carotid trauma were excluded. The remaining 206 patients were evaluated in a cross-sectional study in which their clinical, ethnic and demographic characteristics were collected (Table I). Ethnic differences were defined by phenotypic observation, direct questions regarding the patients' ancestors and patients' ethnic self-identification. Patients were then divided into two major groups: Euro-descendants (Caucasians) and Afro-descendants. IMT values were compared between the ethnic groups, initially using the entire patient population, and subsequently in subgroup analyses. For the subgroup analyses included in this study, patients were stratified by IMT (normal vs. increased), presence of neurologic symptoms (yes vs. no) and presence of carotid stenosis (yes vs. no).

All ultrasound examinations were performed by a single physician, who was certified to perform duplex scan diagnostic procedures. Initially, ultrasound examinations were performed using an ATL HDI 1500 ultrasound system (Phillips Medical Systems, Bothell, WA, USA) with a 10-12 $\mathrm{MHz}$ linear transducer. In the more recent cases, a Logiq 5 ultrasound system (GE Healthcare, Milwaukee, WI, USA) with a $10 \mathrm{MHz}$ linear transducer was used. Duplex scan of the carotid and vertebral vessels was performed according to standard techniques. The degree of internal carotid artery (ICA) stenosis was classified according to the Society for Radiologists in Ultrasound ${ }^{18}$ criteria.

For the IMT measurements, the CCA was scanned using two longitudinal views, posterolateral and anterolateral, as previously described. ${ }^{19}$

IMT evaluation was performed on both CCAs, except in five cases, in which only unilateral IMT evaluation was performed due to unilateral CCA occlusion. At least three IMT measurements for both the near and far wall were obtained for each CCA, for a total of 12 measurements per vessel. The mean value of these measurements from both CCAs was calculated. Additionally, the mean and maximum IMT values of each CCA were used for comparison of IMT values between sides. Ultrasound B-mode settings, including gain, depth, focal zone placement and compression, were individually adjusted to each vessel in order to enhance

Table I - Clinical and demographic characteristics stratified by ethnic group

\begin{tabular}{|c|c|c|c|c|}
\hline & $\begin{array}{l}\text { All study participants } \\
(\mathrm{n}=206)\end{array}$ & $\begin{array}{l}\text { Euro-descendants } \\
\mathrm{n}=121(58.7 \%)\end{array}$ & $\begin{array}{l}\text { Afro-descendants } \\
\mathrm{n}=85(41.3 \%)\end{array}$ & $\mathrm{p}$ \\
\hline \multirow[t]{2}{*}{ Age (years, mean \pm SD) } & $60.8 \pm 12.9$ & $61.5 \pm 12.7$ & $59.7 \pm 13.1$ & .32 \\
\hline & $\mathrm{N}(\%)$ & $\mathrm{N}(\%)$ & $\mathrm{N}(\%)$ & \\
\hline Age $>59$ years & 109 (52.9) & $68(56.2)$ & $41(48.2)$ & .31 \\
\hline Male sex & $106(51.5)$ & $66(54.5)$ & $40(47.1)$ & .35 \\
\hline Arterial Hypertension & $172(83.5)$ & $101(83.5)$ & $71(83.5)$ & .99 \\
\hline Diabetes Mellitus & $49(23.8)$ & $29(24.0)$ & $20(23.5)$ & .99 \\
\hline Smoking & $72(34.9)$ & $46(38.0)$ & $25(30.1)$ & .32 \\
\hline Stroke & $129(62.6)$ & $76(62.8)$ & $53(62.4)$ & .99 \\
\hline TIA & $11(5.3)$ & $6(5.0)$ & $5(5.9)$ & .99 \\
\hline Stroke / TIA & $139(67.5)$ & $81(66.9)$ & $58(68.2)$ & .96 \\
\hline $\begin{array}{l}>50 \% \text { ICA stenosis or occlu- } \\
\text { sion* }\end{array}$ & $32(15.6)$ & 25 (20.7) & $7(8.2)$ & .02 \\
\hline
\end{tabular}

*Three cases of bilateral disease 
Table II - Comparison of left and right common carotid artery intima-media thickness

\begin{tabular}{|c|c|c|c|c|c|c|}
\hline & \multicolumn{2}{|c|}{ Mean IMT (mm) } & \multirow[t]{2}{*}{$\mathrm{p}$} & \multicolumn{2}{|c|}{ Maximum IMT (mm) } & \multirow[t]{2}{*}{$\mathrm{p}$} \\
\hline & Left CCA & Right CCA & & Left CCA & Right CCA & \\
\hline Patients with normal IMT & $7.28 \pm 1.17$ & $7.38 \pm 1.15$ & 0.524 & $8.09 \pm 1.38$ & $8.26 \pm 1.32$ & 0.415 \\
\hline Patients with increased IMT & $14.4 \pm 5.9$ & $13.0 \pm 4.6$ & 0.004 & $16.49 \pm 6.74$ & $14.89 \pm 5.53$ & 0.004 \\
\hline All patients & $12.54 \pm 6.0$ & $11.51 \pm 4.7$ & 0.005 & $14.28 \pm 6.9$ & $13.14 \pm 5.6$ & 0.007 \\
\hline
\end{tabular}

CCA: common carotid artery; IMT: intima-media thickness

visualization of arterial wall structures and image quality. IMT was measured by manual techniques, and values greater than $1.0 \mathrm{~mm}$ were considered to be abnormal.

Statistics: Differences in risk factor distributions among ethnic groups were calculated using chi-square analysis and the Student's t-test. The association between increased IMT and clinical characteristics was investigated using univariate (Student's t-test, Spearman's correlation) and multivariate (logistic regression) analyses. Differences in IMT measurements between ethnic groups were calculated using Student's t-test. Differences in IMT measurements between left and right common carotid arteries were estimated using a paired-sample t-test.

\section{RESULTS}

The average age of the study population is $60.8 \pm 12.9$ years. Similar numbers of male and female individuals were included. Detailed demographic and clinical characteristics of the patients are listed in Table I. Afro-descendants were found to have a lower rate of $>50 \%$ internal carotid stenosis than Euro-descendants. No other differences were observed between the baseline characteristics of the two ethnic groups. Of the 206 patients studied, $153(74.3 \%)$ had a CCA IMT greater than $1.0 \mathrm{~mm}$ in at least one common carotid artery and at one or more measurement points. Additionally, 116 (56.3\%) patients had a mean CCA IMT greater than $1.0 \mathrm{~mm}$. Increased IMT was found bilaterally in 116 patients (56.3\%). Of patients with unilaterally increased IMT, increased IMT was observed in 16 left and 16 right carotid arteries.

Differences were evident when IMT measurements were compared between left and right common carotid arteries. Patients with increased IMT had higher mean and maximum measurement values in the left carotid artery. Among patients with normal IMT values, no statistical differences were observed between sides. These findings are detailed in Table II.

A significant correlation was observed between increasing age and mean bilateral carotid wall thickness $(\mathrm{R}=0.479, \mathrm{P}<0.01$; Figure I).

Univariate analysis revealed an association between the following variables and increased mean and maximum IMT

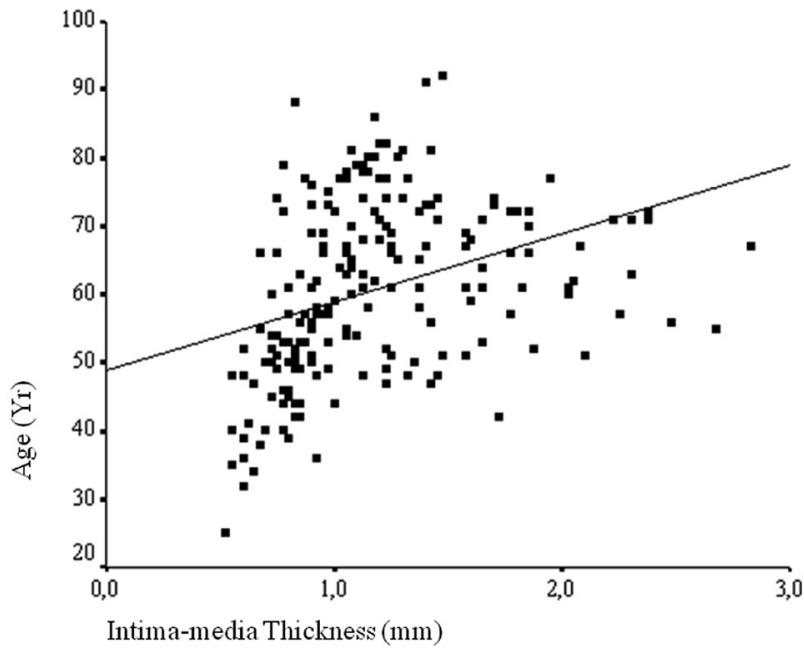

Figure 1 - Correlation between increasing age and mean bilateral carotid wall intima-media thickness.

values: male sex, arterial hypertension and age greater than 59 years. ICA stenosis rates that were greater than $50 \%$ were related to an increase in maximum IMT values. Smoking and previous neurological events (stroke and/or TIA) were not associated with increased IMT in this study (Table III).

When IMT was compared between ethnic groups using Student's t-test, no significant differences between those of European descent and those of African descent were observed. When patients were stratified by IMT thickness (normal vs. increased), the presence of stroke and/or TIA (yes vs. no) or the presence of carotid stenosis (yes vs. no) no differences were found between Euro- and Afrodescendants. Detailed results of these analyses are presented in Table IV.

Multivariate analysis identified male sex, arterial hypertension, and increasing age as variables associated with increased IMT $(\mathrm{P}<.05$ for all variables; Table V).

\section{DISCUSSION}

IMT measurement by ultrasound is widely regarded as an accurate tool for screening and assessment of cardiovascular risk. 
Table III - Risk factors associated with increased IMT*

\begin{tabular}{|c|c|c|c|c|c|}
\hline & & Mean IMT $($ mean \pm SD) & $\mathrm{p}$ & $\begin{array}{c}\text { Maximum IMT } \\
(\text { mean } \pm \text { SD })\end{array}$ & $\mathrm{p}$ \\
\hline \multirow[t]{2}{*}{ Sex } & Male & $12.46 \pm 4.72$ & .02 & $16.29 \pm 7.5$ & .01 \\
\hline & Female & $11.01 \pm 4.19$ & & $13.83 \pm 6.52$ & \\
\hline \multirow[t]{2}{*}{ Age $>59$ years } & $>59 \mathrm{yr}$ & $13.25 \pm 4.29$ & $<.001$ & $16.9 \pm 6.83$ & $<.001$ \\
\hline & Up to $59 \mathrm{yr}$ & $10.10 \pm 4.24$ & & $13.04 \pm 6.98$ & \\
\hline \multirow[t]{2}{*}{ Systemic hypertension } & Yes & $12.30 \pm 4.53$ & $<.001$ & $15.88 \pm 7.2$ & $<.001$ \\
\hline & No & $09.14 \pm 3.47$ & & $11.15 \pm 4.8$ & \\
\hline \multirow[t]{2}{*}{ Diabetes } & Yes & $11.50 \pm 3.88$ & .61 & $14.57 \pm 6.2$ & .53 \\
\hline & No & $11.88 \pm 4.72$ & & $15.29 \pm 7.4$ & \\
\hline \multirow[t]{2}{*}{ Smoking } & Yes & $12.85 \pm 5.08$ & .088 & $16.19 \pm 7.5$ & .12 \\
\hline & No & $11.35 \pm 4.17$ & & $14.57 \pm 6.9$ & \\
\hline \multirow[t]{2}{*}{ Stroke } & Yes & $11.80 \pm 4.66$ & .88 & $15.19 \pm 7.5$ & .80 \\
\hline & No & $11.71 \pm 4.33$ & & $14.94 \pm 6.5$ & \\
\hline \multirow[t]{2}{*}{ TIA } & Yes & $11.27 \pm 3.18$ & .70 & $13.18 \pm 4.0$ & .36 \\
\hline & No & $11.79 \pm 4.59$ & & $15.21 \pm 7.2$ & \\
\hline \multirow[t]{2}{*}{ Stroke or TIA } & Yes & $11.77 \pm 4.56$ & .98 & $15.06 \pm 7.3$ & .92 \\
\hline & No & $11.760 \pm 4.47$ & & $15.16 \pm 6.8$ & \\
\hline \multirow[t]{2}{*}{ ICA stenosis $\dagger$} & $>50 \%$ & $13.35 \pm 6.31$ & .06 & $14.94 \pm 6.9$ & .049 \\
\hline & $<50 \%$ & $11.63 \pm 5.17$ & & $12.82 \pm 6.0$ & \\
\hline
\end{tabular}

*Univariate analysis results

TIA, transient ischemic attack; ICA, internal carotid artery. $† \mathrm{~N}=407$

Table IV - Comparison of mean and maximum values of intima-media thickness (IMT) between Caucasians and Afrodescendants*

\begin{tabular}{|c|c|c|c|c|c|c|}
\hline & $\mathrm{N}$ & & All patients & Caucasians & Afro-descendants & $\mathrm{p}$ \\
\hline \multirow[t]{2}{*}{ IMT up to $1.0 \mathrm{~mm}$} & 61 & Mean CIMT & $7.56 \pm 1.0$ & $7.7 \pm 0.9$ & $7.3 \pm 1.2$ & .20 \\
\hline & & Maximum CIMT & $8.69 \pm 1.0$ & $8.8 \pm 1.0$ & $8.4 \pm 1.0$ & .20 \\
\hline \multirow[t]{2}{*}{ IMT $>1.0 \mathrm{~mm}$} & 145 & Mean CIMT & $13.6 \pm 4.1$ & $13.7 \pm 4.2$ & $13.5 \pm 4.2$ & .79 \\
\hline & & Maximum CIMT & $17.7 \pm 6.8$ & $17.8 \pm 6.7$ & $17.6 \pm 7.1$ & .85 \\
\hline \multirow[t]{2}{*}{ No neurologic events } & 67 & Mean CIMT & $11.7 \pm 4.4$ & $11.9 \pm 4.3$ & $11.4 \pm 4.7$ & .64 \\
\hline & & Maximum CIMT & $15.1 \pm 6.8$ & $15.3 \pm 6.6$ & $14.9 \pm 7.1$ & .84 \\
\hline \multirow[t]{2}{*}{ Stroke and/or TIA $\dagger$} & 139 & Mean CIMT & $11.8 \pm 4.5$ & $11.9 \pm 4.5$ & $11.7 \pm 4.5$ & .90 \\
\hline & & Maximum CIMT & $15.0 \pm 7.3$ & $15.1 \pm 7.2$ & $14.9 \pm 7.4$ & .89 \\
\hline \multirow[t]{2}{*}{ Carotid stenosis $<50 \%$} & 173 & Mean CIMT & $11.5 \pm 4.4$ & $11.5 \pm 4.4$ & $11.4 \pm 4.5$ & .88 \\
\hline & & Maximum CIMT & $14.7 \pm 6.9$ & $14.7 \pm 6.8$ & $14.6 \pm 7.0$ & .94 \\
\hline \multirow[t]{2}{*}{ Carotid stenosis $>50 \%$} & 32 & Mean CIMT & $13.0 \pm 4.6$ & $13.0 \pm 4.4$ & $12.8 \pm 5.5$ & .94 \\
\hline & & Maximum CIMT & $17.0 \pm 8.1$ & $16.8 \pm 7.7$ & $17.7 \pm 10.3$ & .81 \\
\hline \multirow[t]{2}{*}{ All patients } & 206 & Mean CIMT & $11.8 \pm 4.51$ & $11.9 \pm 4.4$ & $11.7 \pm 4.5$ & .21 \\
\hline & & Maximum CIMT & $15.1 \pm 7.14$ & $15.1 \pm 7.0$ & $14.9 \pm 7.3$ & .23 \\
\hline
\end{tabular}

* Analysis was performed using Student's t-test

$\dagger$ Transient ischemic attack

Table V - Risk factors associated with an IMT greater than 1.0mm*

\begin{tabular}{lccc}
\hline Variable & Hazard Ratio (Relative risk) & 95\% Hazard Ratio Confidence Limits & $\mathrm{p}$ \\
\hline Increasing Age & 1.115 & $1.075-1.158$ & .000 \\
Systemic hypertension & 2.690 & $1.043-6.935$ & .041 \\
Male sex & 2.160 & $1.021-4.570$ & .044 \\
\hline
\end{tabular}

* Results are from multivariate analysis. 
Many studies evaluating IMT in specific ethnic groups have been previously undertaken. They have shown similar results regarding the association of IMT with risk factors for atherosclerosis and cardiovascular diseases..$^{20}$ However, the roles of genetic differences in intima-media thickening, atherogenesis, plaque development and evolution, as well as in the natural history of cardiovascular disease have not been fully elucidated.

A prior study found lower CCA IMT values among in Afro-descendants with type 2 diabetes as compared to Euro-descendants with type 2 diabetes with similar social and cardiovascular profiles. This finding suggests that there may be ethnic differences in the response of the CCA wall to diabetes and its related metabolic changes. ${ }^{21}$

Conversely, the PARC-AALA ${ }^{22}$ multicenter investigation revealed that the ethnically distinct populations included in the study had similar rates of increased CCA IMT that were directly related to the presence of cardiovascular disease risk factors. This study identified lower CCA IMT values between eastern Asians in comparison with individuals from Latin America, Africa and the Middle East. Such differences were directly related to a lower incidence of cardiovascularrelated risk factors among eastern Asians.

The Brazilian population has unique ethnic characteristics. The majority of the population is of European or African descent, and there is a high degree of miscegenation. In this study, the two main ethnic groups that comprise the majority of the Brazilian population were investigated. Patients in the Afro-descendant and Eurodescendant groups had very similar baseline characteristics in terms of age, gender distribution, the prevalence of cardiovascular risk factors and the prevalence of previous neurologic events linked to atherosclerotic disease. There were no differences noted in IMT values between patients of African descent and those of European descent in this study. The two ethnic groups had very similar baseline clinical and demographic characteristics. The similarities in CCA IMT values also remained following subgroup analysis. Such observations suggest that clinical characteristics and lifestyle habits associated with cardiovascular events play a more important role in carotid intimomedial thickening than ethnic-related genetic factors. This finding is consistent with the evidences pointed in a previous study. ${ }^{23}$

A possible limitation of our study is that the number of racially mixed individuals may be higher than is apparent. Simple phenotype observation and genealogic questionnaires may have low accuracy in determining racial identity. Because of this complicated issue, our initial intention to divide the study population into three groups of individuals, with the third category being one of mixed European/African descent, was abandoned.
Another minor ethnic group, Japanese/Chinese descendants, which represents $0.54 \%$ of the Brazilian population, ${ }^{24}$ was not included in this investigation. This omission is likely because this patient population generally seeks care at private healthcare facilities, which is not the profile of our institution. Further studies should to be undertaken in order to collect information about the common carotid artery IMT profile of these individuals. The impact of the Westernized Brazilian lifestyle on oriental descendants in terms of cardiovascular disease markers and status also provides an area for further study.

IMT was previously reported to be a marker for cerebrovascular disease and stroke. ${ }^{25-26}$ Approximately twothirds of our patients had a prior recent history of stroke and/or TIA. No differences were observed between IMT values in patients who had experienced cerebrovascular events as compared to those who had not, in the entire study population or the individual ethnic subgroups. Clearly, the value of CCA IMT for predicting stroke or TIA events are best confirmed by longitudinal investigations, while cross-sectional studies like ours may fail to identify this relationship. However, the very weak association between CCA IMT and cerebrovascular disease observed in our investigation reinforces the concept that other etiologic factors, such as arrhythmias or non-embolic events, may be included in investigational models for stroke risk.

A significant difference in the incidence of ICA stenosis was observed between Afro-descendants and Euro-descendants, with ICA stenosis occurring far more frequently in Euro-descendants. This finding confirms previous reports of higher rates of carotid stenosis among Caucasians. ${ }^{27}$ Furthermore, maximum IMT values were significantly higher in patients with ICA stenosis. However, IMT values increased similarly for both ethnic groups in the presence of ICA stenosis, with no observable differences between the two groups (Table IV). The finding that Afrodescendants have a lower incidence of ICA stenosis than Afro-descendants despite similar age and risk factor profiles is important and needs further investigation. Due to the small number of patients with ICA stenosis identified in this study and the limitations imposed by a cross-sectional study design, we felt that no further conclusions could be obtained from our data.

In this investigation, mean IMT values differed between the left and right sides. In individuals with normal IMT values, both CCAs had similar IMTs. However, in individuals with increased IMT, left CCA IMT mean values were statistically significantly higher than right CCA IMT values. Such evidence is compatible with previous findings ${ }^{28}$ that left CCAs have a trend of developing increased IMT earlier than right CCAs. This finding can likely be 
explained by differences in anatomy that expose the left CCA to a higher wall shear stress than the right CCA, and consequently to wall abnormalities, when other risk factors are present.

Intima-media thickness directly correlated with increasing age in this study. This finding may be explained by the observation that older individuals tend to have a higher prevalence of risk factors for atherosclerotic disease than younger persons, and have been exposed to these risk factors for a longer period of time. Thus, older age may not be a risk factor; rather, it may exert an indirect influence on IMT values. This observation may have influenced the results obtained in our multivariate analysis.

Systemic hypertension was clearly associated with increased IMT, both in univariate and multivariate analysis, as has been widely observed in previous investigations. ${ }^{29-31}$ Chronic systemic hypertension is one of the most important factors associated with arterial wall shear stress, and direct control of hypertension may lead to a decrease in IMT values, as has been revealed by longitudinal studies. ${ }^{9}$

Our results revealed that male individuals have significantly higher mean IMT values than females $(12.46 \pm 4.72$ vs. $11.01 \pm 4.19 ; p=.01)$, despite the lack of significant differences in age or prevalence of arterial hypertension in our sample (results not presented). Other studies have found that males have an increased prevalence of coronary events, even when compared to females with similar prevalence and duration of exposure to atherosclerotic risk factors. ${ }^{32-33}$ However, these patterns cannot be fully extrapolated to other sites of vascular disease, and gender-related differences in cardiovascular disease have not been fully elucidated. ${ }^{34}$

Recent studies have revealed a tendency of investigators to use the mean maximum thickness of the CCA, carotid bulbs and ICA in their analyses. ${ }^{35} \mathrm{We}$ avoided this approach for several reasons. Notably, while carotid bulb and ICA measurements may be useful, they can be measured only in limited angles that may not reflect the thickest portions of the vessel wall. ${ }^{36-37}$ The variance of results of bulb and ICA IMT amongst repeated examinations and different physicians is also higher than with CCA measurements. ${ }^{38-40}$ Finally, up to $52 \%$ of images can fail to obtain accurate bulb and ICA measurements. ${ }^{41}$

The cross-sectional design of this investigation has clear limitations. Although it revealed several clinical and demographic factors associated with increased CCA IMT, it may have underestimated other important features that characterize the development of atherosclerotic disease and its associated early arterial wall changes. Dyslipidemia is one of these features, and its effects on IMT would be better evaluated in a longitudinal investigation. Also, the time of onset of other classic cardiovascular risk factors, such as diabetes and systemic hypertension, are essential for evaluation of their proportional and gradual effects on the arterial wall.

\section{CONCLUSIONS}

The risk factors associated with increased CCA IMT in Brazilian individuals are similar to those identified in previously described populations. No differences in CCA IMT were observed between the two main Brazilian ethnic groups. Longitudinal studies are required for better comprehension of the incidence, etiologic factors and evolution of carotid intimomedial thickening in this population.

\section{ACKNOWLEDGEMENTS}

In the loving memory of Dr. Maria Alice Bosch.

\section{REFERENCES}

1. Pignoli P, Tremoli E, Poli A, Oreste P, Paoletti R. Intimal plus medial thickness of the arterial wall: a direct measurement with ultrasound imaging. Circulation. 1986;74:1399-406.

2. Wong M, Edelstein J, Wollman J, Bond G. Ultrasonic-pathological comparison of the human arterial wall: verification of intimamedia thickness. Arterioscler Thromb. 1993;13:482-6.

3. Baldassarre D, Amato M, Bondioli A, Sirtori CR, Tremoli E. Carotid artery intima-media thickness measured by ultrasonography in normal clinical practice correlates well with atherosclerosis risk factors. Stroke. 2000;31:2426-30.
4. Zureik M, Ducimetière P, Touboul PJ, Courbon D, Bonithon-Kopp $\mathrm{C}$, Berr C, et al. Common carotid intima-media thickness predicts occurrence of carotid atherosclerotic plaques: longitudinal results from the Aging Vascular Study (EVA) study. Arterioscler Thromb Vasc Biol. 2000;20:1622-9.

5. Craven TE, Ryu JE, Espeland MA, Kahl FR, McKinney WM, Toole JF, et al. Evaluation of the association between carotid artery atherosclerosis and coronary artery stenosis: a case-control study. Circulation. $1990 ; 82: 1230-42$ 
6. Burke GL, Evans GW, Riley WA, Sharrett AR, Howard G, Barnes RW, et al. Arterial wall thickness is associated with prevalent cardiovascular disease in middle aged adults: the Atherosclerosis Risk in Communities (ARIC) Study. Stroke. 1995;26:386-91.

7. Allan PL, Mowbray PI, Lee AJ, Fowkes FGR. Relationship between carotid intima-media thickness and symptomatic and asymptomatic peripheral arterial disease: the Edinburgh Artery Study. Stroke. $1997 ; 28: 348-53$

8. Holaj R, Spacil J, Petrasek J, Malik J, Haas T, Aschermann M. Intimamedia thickness of the common carotid artery is the significant predictor of angiographically proven coronary artery disease. Can J Cardiol. 2003;19:670-6

9. Boutouyrie P, Bussy C, Hayoz D, Hengstler J, Dartois N, Laloux B, et al. Local pulse pressure and regression of arterial wall hypertrophy during long-term antihypertensive treatment. Circulation. 2000;101:2601-6.

10. van Tits LJ, Smilde TJ, van Wissen S, de Graaf J, Kastelein JJ, Stalenhoef AF. Effects of atorvastatin and simvastatin on low-density lipoprotein subfraction profile, low-density lipoprotein oxidizability, and antibodies to oxidized low-density lipoprotein in relation to carotid intima media thickness in familial hypercholesterolemia. J Investig Med. 2004;52:17784.

11. Nagasaki T, Inaba $M$, Henmi $Y$, Kumeda $Y$, Ueda $M$, Tahara $H$, et al. Decrease in carotid intima-media thickness in hypothyroid patients after normalization of thyroid function. Clin Endocrinol (Oxf). 2003;59:60712.

12. Markus RA, Mack WJ, Azen SP, Hodis HN. Influence of lifestyle modification on atherosclerotic progression determined by ultrasonographic change in the common carotid intima-media thickness. Am J Clin Nutr. 1997;65:1000-4.

13. Woo KS, Chook P, Raitakari OT, McQuillan B, Feng JZ, Celermajer DS. Westernization of Chinese adults and increased subclinical atherosclerosis. Arterioscler Thromb Vasc Biol. 1999;19:2487-93.

14. D'Agostino RB Jr, Burke G, O’Leary D, Rewers M, Selby J, Savage PJ, et al. Ethnic differences in carotid wall thickness. The Insulin Resistance Atherosclerosis Study. Stroke. 1996;27:1744-9.

15. Juonala M, Viikari JS, Kähönen M, Taittonen L, Rönnemaa T, Laitinen T, et al. Geographic origin as a determinant of carotid artery intima-media thickness and brachial artery flow-mediated dilation: the Cardiovascular Risk in Young Finns study. Arterioscler Thromb Vasc Biol. 2005;25:3928 .

16. Martinez LR, Miname MH, Bortolotto LA, Chacra AP, Rochitte CE, Sposito AC, et al. No correlation and low agreement of imaging and inflammatory atherosclerosis markers in familial hypercholesterolemia. Atherosclerosis. 2008;200:83-8.

17. Pereira I, Laurindo I, Burlingame R, Anjos L, Viana V, Leon E, et al. Auto-antibodies do not influence development of atherosclerotic plaques in rheumatoid arthritis. Joint Bone Spine. 2008;75:416-21.

18. Grant EG, Benson CB, Moneta GL, Alexandrov AV, Baker JD, Bluth EI, et al. Carotid artery stenosis: gray-scale and Doppler US diagnosis-Society of Radiologists in Ultrasound Consensus Conference. Radiology. 2003;229:340-6.

19. Casella IB, Presti C, Porta RM, Sabbag CR, Bosch MA, Yamazaki Y. A practical protocol to measure common carotid artery intima-media thickness. Clinics. 2008;63:515-20.
20. Salonen R, Salonen JT. Determinants of carotid intima-media thickness: a population-based ultrasonography study in eastern Finnish men.J Intern Med. 1991;229:225-31

21. Freedman BI, Hsu FC, Langefeld CD, Rich SS, Herrington DM, Carr $\mathrm{JJ}$, et al. The impact of ethnicity and sex on subclinical cardiovascular disease: the Diabetes Heart Study. Diabetologia. 2005;48:2511-8.

22. Touboul PJ, Hernández-Hernández R, Küçüko lu S, Woo KS, Vicaut E, Labreuche J, et al. PARC-AALA Investigators. Carotid artery intima media thickness, plaque and Framingham cardiovascular score in Asia, Africa/Middle East and Latin America: the PARC-AALA study. Int J Cardiovasc Imaging. 2007;23:557-67.

23. Watanabe H, Yamane K, Fujikawa R, Okubo M, Egusa G, Kohno N Westernization of lifestyle markedly increases carotid intima-media wall thickness (IMT) in Japanese people. Atherosclerosis. 2003;166:67-72.

24. http://www.ibge.gov.br/home/estatistica/populacao/ trabalhoerendimento/pnad2005/brasil/tabbr_1_1_e_1_2.pdf

25. Lorenz MW, Markus HS, Bots ML, Rosvall M, Sitzer M. Prediction of Clinical Cardiovascular Events With Carotid Intima-Media Thickness A Systematic Review and Meta-Analysis. Circulation. 2007;115:459-467.

26. Lee EJ, Kim HJ, Bae JM, Kim JC, Han HJ, Park CS, et al. Relevance of Common Carotid Intima-Media Thickness and Carotid Plaque as Risk Factors for Ischemic Stroke in Patients with Type 2 Diabetes Mellitus. AJNR Am J Neuroradiol. 2007;28:916-9.

27. Wang MY, Mimran R, Mohit A, Lavine SD, Giannotta S. Carotid stenosis in a multiethnic population. J Stroke Cerebrovasc Dis. 2000;9:64-9.

28. Rodríguez Hernández SA, Kroon AA, van Boxtel MPJ, Mess WH, Lodder $\mathrm{J}$, Jolles $\mathrm{J}$, et al. Is there a side predilection for cerebrovasculardisease? Hypertension. 2003;42:56-60.

29. Roman MJ, Saba PS, Pini R, Spitzer M, Pickering TG, Rosen S, et al. Parallel cardiac and vascular adaptation in hypertension. Circulation. 1992;86:1909-18

30. Girerd X, Mourad JJ, Copie X, Moulin C, Acar C, Safar M, et al. Noninvasive detection of an increased vascular mass in untreated hypertensive patients.Am J Hypertens. 1994;7:1076-84.

31. Stary HC, Blankenhorn DH, Chandler AB, Glagov S, Insull W Jr, Richardson M, et al. A definition of the intima of human arteries and of its atherosclerosis-prone regions. A report from the Committee on Vascular Lesions of the Council on Arteriosclerosis, American Heart Association. Arterioscler Thromb. 1992;12:120-34.

32. Wingard DL, Suarez L, Barrett-Connor E. The sex differential in mortality from all causes and ischemic heart disease. Am J Epidemiol. $1983 ; 117: 165-72$

33. Barrett-Connor E. Sex differences in coronary heart disease. Why are women so superior? The 1995 Ancel Keys Lecture. Circulation. 1997;95:252-64.

34. Kardys I, Vliegenthart R, Oudkerk M, Hofman A, Witteman JC. The female advantage in cardiovascular disease: do vascular beds contribute equally? Am J Epidemiol. 2007;166:403-12.

35. Bots ML, Evans GW, Riley WA, Grobbee DE. Carotid intima-media thickness measurements in intervention studies: design options, progression rates, and sample size considerations: a point of view. Stroke. 2003;34:2985-94 
36. Mack WJ, Selzer RH, Hodis HN, Erickson JK, Liu CR, Liu CH, et al. One-year reduction and longitudinal analysis of carotid intimamedia thickness associated with colestipol/niacin therapy. Stroke. 1993:24:1779-83.

37. Furberg CD, Adams HP Jr, Applegate WB, Byington RP, Espeland MA, Hartwell T, et al. for the Asymptomatic Carotid Artery Progression Study (ACAPS) Research Group. Effect of lovastatin on early carotid atherosclerosis and cardiovascular events. Circulation. 1994;90:1679-87.

38. O'Leary DH, Polak JF, Wolfson SK Jr, Bond MG, Bommer W, Sheth $\mathrm{S}$, et al. Use of sonography to evaluate carotid atherosclerosis in the elderly: the cardiovascular health study. Stroke. 1991;22:1155-63.
39. Crouse JR III, Craven TE, Hagaman AP, Bond MG. Association of coronary disease with segment-specific intimal-medial thickening of the extracranial carotid artery. Circulation. 1995;92:1141-47.

40. Stensland-Bugge E, Bønaa KH, Joakimsen O. Reproducibility of ultrasonographically determined intima-media thickness is dependent on arterial wall thickness: the Troms $\varnothing$ study. Stroke. 1997;28:1972-80.

41. Howard G, Sharrett AR, Heiss G, Evans GW, Chambless LE, Riley WA, et al. Carotid artery intimalmedial thickness distribution in general populations as evaluated by B-mode ultrasound. Stroke. 1993;24:1297304 